\title{
CLINICAL PROFILE OF HENOCH-SCHONLEIN PURPURA IN CHILDREN
}

\author{
Deepa Kunju Krishnan1, Bindu Krishnan Padma²
}

${ }_{1}^{1}$ Assistant Professor, Department of Paediatrics, Government Medical College, Kottayam, Kerala, India.

${ }^{2}$ Assistant Professor, Department of Paediatrics, Government Medical College, Kottayam, Kerala, India.

\section{BACKGROUND}

\section{ABSTRACT}

Henoch-Schonlein purpura (HSP) is the most common systemic vasculitis in children. It can produce multisystem involvement. The disease is usually self-limited, but can occasionally produce life-threatening gastrointestinal and renal manifestations.

The aim of the study is to describe the age of onset and clinical profile of HSP in children.

\section{MATERIALS AND METHODS}

This is a retrospective descriptive study conducted in a tertiary care hospital. 61 children below 12 years who were admitted over a 2-year period with a diagnosis of HSP based on American College of Rheumatology criteria were included in the study. The clinical details were collected from the case records and entered in a proforma. Data was analysed statistically.

\section{RESULTS}

The mean age of presentation was 6.7 years. The male-to-female ratio was 1.2: 1 . The commonest clinical features were purpura (100\%), abdominal pain (70\%) and arthritis (65\%). Renal involvement was seen in 5\%. Anaemia was seen in $48 \%$, raised ESR in $50 \%$ and thrombocytosis in $20 \%$. Steroids were used in treatment in $55 \%$ of patients.

\section{CONCLUSION}

The clinical profile of HSP in children was similar to that found in other studies except for renal involvement, which showed much lower incidence in this study. Gastrointestinal manifestations and arthritis may occasionally be the presenting features of HSP even before appearance of rash. Steroids were used in more than half of the patients with HSP.

\section{KEY WORDS}

Clinical Profile, Henoch-Schonlein Purpura, Children.

HOW TO CITE THIS ARTICLE: Krishnan DK, Padma BK. Clinical profile of Henoch-Schonlein purpura in children. J. Evolution Med. Dent. Sci. 2018;7(22):2671-2673, DOI: 10.14260/jemds/2018/601

\section{BACKGROUND}

Henoch-Schonlein Purpura is the most common systemic vasculitis in children. ${ }^{1}$ The annual incidence of HSP in children is $14-20$ per one lakh population.2,3 The hallmark of HSP is non-thrombocytopenic palpable purpura. It can produce multisystem involvement, especially joint, renal and gastrointestinal manifestations. The disease usually has a self-limited course. However, occasionally life-threatening complications like gastrointestinal bleed and renal disease can be seen in HSP. Renal involvement in HSP may occur as late as six months after onset of disease. So, these patients need monthly follow-up for at least upto 6 months after onset of disease. ${ }^{4,5}$ The role of steroids in treatment of HSP is controversial. 6 Increasing awareness regarding the lifethreatening complications of HSP, the chance of delayed renal involvement and the need for judicious use of steroids in treatment of HSP will help in improving the outcome of these patients. There are very few studies on HSP in children from India.

The aim of this study is to describe the age of outcome, clinical features and investigative profile of HSP in children.

'Financial or Other Competing Interest': None.

Submission 09-04-2018, Peer Review 14-05-2018,

Acceptance 17-05-2018, Published 28-05-2018.

Corresponding Author:

Deepa Kunju Krishnan,

Assistant Professor,

Department of Paediatrics,

Government Medical College, Kottayam, Kerala.

E-mail: deepapullayil@yahoo.in

DOI: $10.14260 /$ jemds $/ 2018 / 601$

\section{(c) (i) $(-$}

\section{MATERIALS AND METHODS}

This is a retrospective descriptive study conducted in the Department of Paediatrics, Government Medical College, Kottayam. All children below 12 years of age, admitted with a clinical diagnosis of HSP during the time period from June 2015 to June 2017 were included in the study. The diagnosis of HSP was made on the basis of American College of Rheumatology classification criteria. $^{7}$

\section{Any two of the following must be present-}

1. Palpable purpura.

2. Age at onset less than or equal to 20 years.

3. Bowel angina (post-prandial abdominal pain; bloody diarrhoea).

4. Biopsy demonstrating intramural granulocytes in small arterioles and/or venules.

The clinical details were collected from the medical records of patients and entered in a proforma. Data was analysed statistically. Continuous variables were expressed as mean \pm standard deviation. Categorical variables were expressed as percentages.

\section{RESULTS}

Sixty-one patients were diagnosed as having HSP. The mean age at presentation was 6.7 years (Range 2 to 11 years). There were 33 boys and 28 girls with a male-female ratio of 1:2: 1 . History of preceding upper respiratory tract infection was present in 18 patients (30\%). The presenting complaint was rash in 41 patients (67\%). Abdominal pain preceded rash in 12 patients (20\%). Arthritis/ arthralgia preceded rash in 8 patients $(13 \%)$. 


\begin{tabular}{|c|c|c|}
\hline Clinical Features & Number & Percentage \\
\hline Purpuric rash & 61 & 100 \\
\hline Subcutaneous oedema & 9 & 15 \\
\hline Abdominal pain & 43 & 70 \\
\hline Vomiting & 13 & 21 \\
\hline Melena & 3 & 5 \\
\hline Arthritis & 40 & 65 \\
\hline Renal involvement & 3 & 5 \\
\hline Scrotal pain and swelling & 4 & 6 \\
\hline \multicolumn{2}{|c|}{ Table 1. Clinical Spectrum of HSP } \\
\hline
\end{tabular}

Skin involvement was seen in all 61 patients. Purpuric rash with predilection for lower extremities was seen in all 61 patients $(100 \%)$, either at presentation or during the course of illness. Subcutaneous oedema was seen in 9 patients (15\%).

Gastrointestinal system was the next most common system to be affected. The manifestations included abdominal pain in 43 patients $(70 \%)$, vomiting in 13 patients $(21 \%)$ and melena in 3 patients (5\%). Intussusception was seen in 2 patients and massive gastrointestinal bleed requiring blood transfusion occurred in one patient. USS abdomen was done in 47 patients and showed bowel wall thickening in 12 patients, free fluid in 5 patients and intussusception in 1 patient. Among the 40 (65\%) with arthritis, knee joint involvement was present in 31 patients (77\%), ankle involvement in (41\%) 16 patients and elbow involvement in (10\%) 4 patients.

Renal involvement was found in 3 patients (5\%), out of which two patients had microscopic haematuria and one had hypertension. Scrotal pain and swelling was seen in 4 patients (6\%), one of whom had testicular torsion.

Anaemia was present in 29 patients (48\%). Raised ESR was seen in 30 patients (50\%). Thrombocytosis was present in 12 patients (20\%). Stool occult blood was present in 12 patients $(20 \%)$. Urine analysis showed haematuria in 2 patients. Skin biopsy was done in one patient, which was consistent with leucocytoclastic vasculitis. 34 patients (55\%) received steroids.

\section{DISCUSSION}

In our study on HSP, the mean age at presentation was 6.7 years. In a study by Nong et al ${ }^{8}$ mean age of onset of HSP was $6.2 \pm 2.5$ years and in another study by Anil et $\mathrm{al}^{9}$ the mean age of onset was $7.9 \pm 2.9$ years. In this study there was a male preponderance, which is similar to that seen in studies by Nong et $\mathrm{al}^{8}$ and Lata Kumar et al.10

The presenting complaint in HSP was purpura in $67 \%$ of patients. Abdominal pain preceded rash in $20 \%$ of patients. In a study by Choong et al,11 abdominal symptoms preceded onset of rash in $14-36 \%$ of patients.

Palpable purpura was seen in $100 \%$ of patients. In a study by Trapani et al,12 purpura occurred in $100 \%$ of patients at some point during the course of the illness.

Gastrointestinal manifestations in a study by Abbas et al ${ }^{13}$ included abdominal pain in 56\%, vomiting in $35 \%$ and melena in $19 \%$. Comparable results to these were observed in our study. Intussusception was seen in 2 patients. Intussusception is a rare complication in $\mathrm{HSP}^{14}$ (Bagga et al). Acute abdomen needing exploratory laparotomy occurred in $4.6 \%$ of patients in a study by Choong et al.11 Surgical exploration of abdomen was done in 3 of our patients.
USS abdomen often reveals abnormalities in HSP. In a study by Connolly, 15 out of 44 patients who had USS abdomen 15 patients had thickened bowel wall, free fluid in 10 and ileus in 5.

Arthritis was seen in $65 \%$ of patients in our study with knee joint being most commonly affected. The incidence of arthritis in our study was lower than that in a study by Jauhola et al, 16 in which $90 \%$ of patients showed evidence of joint involvement. Renal involvement is one of the dreaded manifestations in HSP. However, renal involvement was seen only in $5 \%$ of our patients. Renal involvement in most studies ranged between $11 \%$ and $31 \% .10,13$ The low incidence of renal disease could be due to the retrospective nature of the study. Repeated urine analysis and follow-up may have detected more cases with minor renal involvement.

There is no specific diagnostic test for HSP. Anaemia was seen in $48 \%$ of patients, raised ESR in 50\% and thrombocytosis in $20 \%$. In a study by Abbas et al,13 anaemia was seen in $48 \%$, raised ESR in $48 \%$ and thrombocytosis in $19 \%$ of patients. Stool occult blood was positive in $20 \%$ of patients, which was comparable to that in other studies.

Steroids were used in treatment in $55 \%$ of patients. Steroids ameliorate many of the symptoms of HSP, although they do not alter the ultimate prognosis of the disease. Steroids were used in treatment in $42 \%$ of patients in a study by Abbas et al. 13

\section{CONCLUSION}

The clinical profile of HSP in children was similar to that found in other studies except for renal involvement, which was much lower in this study. HSP is occasionally seen to present with gastrointestinal involvement and arthritis. The occurrence of life-threatening complications in HSP is very rare. Steroids play a role in relieving the symptoms of HSP.

\section{REFERENCES}

[1] Ardoin SP, Fels E. Henoch-Schonlein purpura. In: Kleigman RM, Stanton BF, St. Geme JW, eds. Nelson text book of Pediatrics. India: Elsevier 2016.

[2] Cassidy JT, Petty RE. Vasculitis. In: Textbook of Pediatric. Rheumatology. $5^{\text {th }}$ edn. Philadelphia: W B Saunders Company 2005: p. 496-501.

[3] Gardner-Medwin JM, Dolezalova P, Cummins C, et al. Incidence of HSP, Kawasaki disease and rare vasculitides in children of different ethnic origins. Lancet 2002:360(9341):1197-202.

[4] Jauhola D, Ronkainen J, Koskimies 0, et al. Renal manifestations of HSP in a 6 month prospective study of 223 children. Arch Dis Child 2010;95(11):877-82.

[5] Meadow SR. The prognosis of Henoch Schonlein nephritis. Clin Nephrol 1978;9(3):87-90.

[6] Weiss PF, Feinstein JA, Luan X, et al. Effect of corticosteroids in HSP: a systematic review. Pediatrics 2007;120(5):1079-87.

[7] Mills JA, Michel BA, Bloch DA, et al. The American College of Rheumatology 1990 criteria for classification of Henoch-Schonlein purpura. Arthritis Rheum 1990;33(8):1114-21.

[8] Nong BR, Huang YF, Chuang CM, et al. Fifteen-years of experience of children with HSP in southern Taiwan, 1991-2005. J Microbiol Immunol Infect 2007;40(4):371-6. 
[9] Anil M, Aksu N, Kara OD, et al. Henoch-Schonlein purpura in children from western Turkey: a retrospective analysis of 430 cases. Turk J Pediatr 2009;51(5):429-36.

[10] Kumar L, Singh S, Goraya JS, et al. Henoch-Schonlein purpura: the Chandigarh experience. Indian Pediatrics 1998;35(1):19-25.

[11] Choong CK, Beasley SW. Intra-abdominal manifestations of Henoch-Schonlein purpura. J Pediatr Child Health 1998;34(5):405-9.

[12] Trapani S, Micheli A, Grisolia F, et al. HenochSchonlein purpura in childhood: epidemiological and clinical analysis of 150 cases over a 5-year period and review of literature. Semin Arthritis Rheum 2005;35(3):143-53.
[13] Abbas S, Geetha S, Deepti RV, et al. Clinical profile and outcome of Henoch-Schonlein purpura in a tertiary care hospital in south India. International Journal of Contemporary Peddiatrics 2017;4(3):822-6.

[14] Bagga A, Kabra SK, Srivastava RN, et al. HenochSchonlein purpura in northern Indian children. Indian Pediatr 1991;28(10):1153-7.

[15] Connolly B, O'Halpin D. Sonographic evalution of the abdomen in Henoch-Schonlein purpura. Clin Radiol 1994;49(5):320-3.

[16] Jauhola O, Ronkainen J, Koskimies 0, et al. Clinical course of extrarenal symptoms of HSP: a 6 month prospective study. Arch Dis Child 2010;95(11):871-6. 